\title{
Idiopathic Short Stature
}

National Cancer Institute

\section{Source}

National Cancer Institute. Idiopathic Short Stature. NCI Thesaurus. Code C118689.

Height greater than two standard deviations below the mean for the age and sex of the reference population. 